\title{
The tree-edit-distance, a measure for quantifying neuronal morphology Holger Heumann ${ }^{1}$ and Gabriel Wittum*2
}

\author{
Address: ${ }^{1 S A M}$, ETH-Zürich, Switzerland and ${ }^{2}$ G-CSC, Goethe-University Frankfurt, Kettenhofweg 139, 60325 Frankfurt am Main, Germany \\ Email: Gabriel Wittum* - wittum@g-csc.de \\ * Corresponding author
}

from Eighteenth Annual Computational Neuroscience Meeting: CNS*2009

Berlin, Germany. 18-23 July 2009

Published: 13 July 2009

BMC Neuroscience 2009, I0(Suppl I):P89 doi:I0.I I86/I47I-2202-I0-SI-P89

This abstract is available from: http://www.biomedcentral.com/I47I-2202/I0/SI/P89

(c) 2009 Heumann and Wittum; licensee BioMed Central Ltd.

The shape of neuronal cells strongly resembles botanical trees or roots of plants. To analyze and compare these complex three-dimensional structures it is important to develop suitable methods. We review the so-called treeedit-distance known from theoretical computer science and use this distance to define dissimilarity measures for neuronal cells. This measure intrinsically respects the treeshape. It compares only those parts of two dendritic trees that have similar position in the whole tree. Therefore it can be interpreted as a generalization of methods using vector-valued measures. Moreover, we show that our new measure, together with cluster analysis, is a suitable method for analyzing three-dimensional shape of hippocampal and cortical cells.

\section{References}

I. Queisser G, Bading H, Wittmann M, Wittum G: Filtering, reconstruction and measurement of the geometry of neuron cell nuclei based on confocal microscopy data. Journal of Biomedical Optics 2008.

2. Voßen C, Eberhard J, Wittum G: Modeling and simulation for three-dimensional signal propagation in passive dendrites. Comput Vis Sci 2007, I0:

3. Eberhard JP, Wanner A, Wittum G: NeuGen: A tool for the generation of realistic morphology of cortical neurons and neural networks in 3D. Neurocomputing 2006, 70:327-342.

4. Broser PJ, Schulte R, Roth A, Helmchen F, Waters J, Lang S, Sakmann $B$, Wittum G: Nonlinear anisotropic diffusion filtering of threedimensional image data from 2-photon microscopy. J Biomedical Optics 2004, 9:1253-I 264. 